\title{
Abordagem Ciência, Tecnologia, Sociedade e Ambiente e a perspectiva do estudo implicado no ensino de ciências: um olhar para a Amazônia brasileira
}

Science, Technology, Society and Environment Approach and the perspective of the implicated study in science education: a look at the brazilian Amazon

Dayane Negrão Carvalho Ribeiro ${ }^{1}$ Elizabeth Orofino Lucio² Ana Cristina Pimentel Carneiro de Almeida ${ }^{3}$

\section{Resumo}

Este artigo é resultado da revisão bibliográfica de uma tese e tem como objetivo apresentar um diálogo por meio da abordagem CTSA (Ciência, Tecnologia, Sociedade e Ambiente) com a perspectiva do estudo implicado, que contemple a pesquisa e o ensino de ciências no contexto amazônico. Para isso, retoma a origem do movimento Ciência, Tecnologia e Sociedade, comenta a natureza da implicação e sua relação com a abordagem CTSA, vinculados a três elementos: objetivos; interações entre ciência, tecnologia, sociedade e ambiente; e estratégias de ensino. Além disso, tece uma discussão com os princípios da abordagem como a participação ativa, a dialogicidade e a problematização, associadas à ideia de transformação da realidade. Por fim, defende a perspectiva do estudo implicado para a pesquisa e o ensino de ciências por meio da abordagem CTSA para a Amazônia, considerando a diversidade que a compõe.

Palavras-chave: Abordagem Ciência, Tecnologia e Sociedade; Estudo Implicado; Ensino de Ciências.

\section{Abstract}

This article is the result of a bibliographical review of a thesis and aims to present a dialogue through the STSE (Science, Technology, Society and Environment) approach with the perspective of the implicated study, which includes research and science teaching in the Amazon context. In order to do so, it takes up the origins of the Science, Technology and Society movement, comments on the nature of the implication and its relationship with the STSE approach, linked to three elements: objectives; interactions between science, technology, society and environment; and teaching strategies. In addition, it discusses the

\footnotetext{
${ }^{1}$ Secretaria de Estado de Educação do Pará | dayanenegraocarvalho@gmail.com

2 Universidade Federal do Pará | orofinolucio@gmail.com

${ }^{3}$ Universidade Federal do Pará | anacrispimentel@gmail.com
} 
principles of the approach such as active participation, dialogicity and problematization, associated with the idea of transforming reality. Finally, it defends the perspective of the implicated study in science research and teaching through the STSE approach to the Amazon, considering the diversity that composes it.

Keywords: Science, Technology and Society Approach; Implicated Study; Science teaching.

\section{Introdução}

Ao lidar com o ensino de ciências para alunos que vivem dentro do contexto amazônico, especificamente na Amazônia paraense, temos a oportunidade de reconhecer a sua importância para a formação das pessoas, pela superação de um senso comum pedagógico de que ele se dá pela mera transmissão mecânica de informações. Nesse sentido, o ensino de ciências tem um potencial para a formação crítica, na qual as pessoas sejam capazes de olhar para os modelos de desenvolvimento econômico, político, social, científico, tecnológico e ambiental vislumbrados para a região e para as especificidades dos povos que a compõem.

Quando este ensino está atrelado à pesquisa e à atmosfera de trabalho do professor e pesquisador, vemos que o pressuposto de neutralidade da ciência é contrariado: não há desinteresse e, portanto, nenhuma neutralidade é possível (MARTINS FILHO; NARVAI, 2013). Dito isso, fazemos alguns questionamentos: é possível pensar em um ensino de ciências que abranja a complexidade amazônica e as especificidades dos povos da região? Como ensinar e pesquisar no campo do ensino de ciências que não reforcem os estereótipos de dependência de conhecimentos científicos e tecnológicos e de subcultura da região? O que vem à cabeça quando se fala em estudo implicado e como estar implicado contribui para o ensino de ciências na Amazônia?

Ao dialogar com autores como Delizoicov, Angotti e Pernambuco (2011), vemos que inicialmente é desejável buscar por mudanças didático-pedagógicas, pois ainda precisamos romper as barreiras do ensino de ciências simplista, pressuposto num trabalho didático pedagógico que favorece a indesejável ciência morta. Nesse sentido, é possível promover ações que favoreçam uma ciência para todos, indispensável para a formação para a cidadania, nas quais a linguagem científica esteja presente. É importante que entendamos a ciência e a tecnologia como parte da cultura humana e como indispensável para a formação das pessoas.

As ações propostas envolvem reconstruções didáticas, metodológicas e epistemológicas, assim como ações que envolvem a aproximação entre a pesquisa em ensino de ciências e o ensino de ciências (DELIZOICOV; ANGOTTI; PERNAMBUCO, 2011). Ao nosso ver, e diante das demandas da pesquisa no campo, consideramos a proposição em meio às relações estabelecidas entre esse ensino com seus objetivos, como o letramento científico e a formação para a cidadania, propulsoras para mudanças efetivas, na medida em que são tratadas dentro de propostas que se dediquem a diminuir a distância entre a pesquisa e o ensino, principalmente quando essas ações são olhadas pelo âmbito das relações internas entre ciência, tecnologia e o contexto em que se desenvolvem.

O ensino de ciências e seus propósitos vêm mudando conforme o ideário educacional e no que diz respeito à produção científica e tecnológica (NASCIMENTO; FERNANDES; MENDONÇA, 2010). Muitos desses propósitos, como a formação para a cidadania e para 
uma sociedade justa e igualitária, encontram ancoragem na abordagem Ciência, Tecnologia, Sociedade e Ambiente (SANTOS, 2012).

Destacamos o caráter histórico e formativo da abordagem CTSA por propiciar o desenvolvimento com um olhar diferenciado para o ensino de ciências, vinculada à educação científica do cidadão no contexto autêntico do meio tecnológico, social e ambiental. Por isso, adotamos a ideia de que fazer educação em ciências por meio dessa abordagem envolve implicação. Quando falamos de Amazônia e de um território tão biodiversificado, propostas de ensino e de pesquisas aplicadas sem questionamento e reflexão nem sempre atendem as necessidades das populações que neste território habitam, pois podem reproduzir estereótipos do sistema homogêneo de floresta e de cultura pobre e inferior (LOUREIRO, 2002).

Assim, este artigo, por meio da revisão de literatura, tem como objetivo promover o diálogo sobre a abordagem CTSA, na perspectiva do estudo implicado para o ensino de ciências, o que, consequentemente, traz reflexões para a pesquisa e para o ensino no campo.

Para fins didáticos, o texto está dividido em quatro seções, além desta introdução. Na primeira seção, apresentamos as origens do movimento e nossa opção pela denominação abordagem CTSA, que ajudam a entender os pressupostos iniciais da referida abordagem. A perspectiva do estudo implicado é o objeto de discussão da segunda seção. A terceira seção traz elementos da abordagem CTSA que, ao nosso ver, tem elo com a perspectiva do estudo implicado no campo. Na quarta seção, buscamos ampliar a discussão a fim de defender a abordagem CTSA, na perspectiva do estudo implicado, com o olhar para a Amazônia paraense, como uma das alternativas para a melhoria da educação científica na região. Por fim, trazemos as considerações, procurando responder às perguntas deste artigo.

\section{Breve histórico: do movimento Ciência, Tecnologia, Sociedade para a abordagem CTSA}

A abordagem CTS não surge no ensino de ciências, mas do movimento de contestação social originado, principalmente, após a Segunda Guerra Mundial, em que o otimismo prometido pelo desenvolvimento científico e tecnológico começava a ser revisto e criticado (SANTOS, 2011).

Vários autores como Auler e Bazzo (2001), Santos e Mortimer (2002) e Santos (2011) situam o início do movimento CTS no contexto pós-guerra, tanto em função dos problemas ambientais gerados pelo cenário socioeconômico da Ciência e da Tecnologia como por causa de uma mudança de visão sobre a natureza da ciência e do seu papel na sociedade. O otimismo prometido pelo desenvolvimento científico e tecnológico, pautado no modelo linear de desenvolvimento, de neutralidade da ciência e das decisões tecnocratas, começava a ser criticado e revisto, fazendo com que a ciência e a tecnologia fossem olhadas com um olhar mais holístico.

Os marcos históricos do início do movimento CTS - como o lançamento do Sputnik, em 1957, e as publicações dos livros Primavera Silenciosa, pela bióloga naturalista Rachel Carsons, e A Estrutura das Revoluções Científicas, de Thomas Kuhn, ambos em 1962 - 
propuseram a necessidade de se repensar a relação homem-natureza mediada pela ciência e tecnologia (ARAÚJO; SILVA, 2012).

O ponto-chave do movimento CTS, portanto, é a apresentação da ciência e da tecnologia como um processo ou um produto inerentemente social, em que os elementos não-técnicos, como os valores, a moral, as convicções religiosas, os interesses sociais e as pressões econômicas, desempenham um papel decisivo na sua origem e consolidação. Logo, a ciência e a tecnologia não são uma atividade autônoma. Elas estão vinculadas aos interesses contextuais (CEREZO, 2004; ARAÚJO; SILVA, 2012).

Essa visão configura o movimento CTS num cenário de mudança acadêmica de imagem da ciência e da tecnologia, na qual elas passam a ser vistas como resultado de um processo ou um produto inerentemente social. Nesse debate, o movimento CTS tem consolidado a formação para a cidadania ao invés de pensar a formação de cientistas e postular um novo controle para a atividade científica e tecnológica, reivindicando decisões mais democráticas e um poder de tomada de decisão além daquela vinda das mãos dos especialistas (SANTOS, 2011).

Inicialmente duas tradições se constituíram no movimento CTS: a americana (Estados Unidos e Canadá), de caráter ativista e inserida nos movimentos sociais; e a europeia, marcada pela investigação acadêmica e pelos estudos sociais de ciências. Tanto a pesquisa acadêmica europeia quanto os movimentos ativistas americanos levaram à propagação do movimento CTS para o campo da educação, implicando em mudanças nos conteúdos, nas metodologias e nas atitudes de alunos e professores. Convém assinalar, portanto, que hoje tanto a tradição europeia quanto a americana podem ser vistas como complementares, precisamente quando olhamos para a essência delas: uma mudança de valores e uma melhor compreensão da ciência e da tecnologia (AULER; BAZZO, 2001; CEREZO, 2004; DOMICIANO, 2019).

Já na Amarica Latina, temos o surgimento de discussões sobre as questões de ciência e tecnologia (CT), o que ficou conhecido como Pensamento Latino-Americano de Ciência, Tecnologia e Sociedade (PLACTS), criado entre as décadas de 50 e 70, que se constituiu como um pensamento coerente, destacando o caráter social da ciência e da tecnologia e criticando a relação de dependência aos países desenvolvidos. O PLACTS, termo criado por Dagnino, Thomas e Davyt (1996), se desenvolveu em meio às críticas de importação de CT e em resposta às demandas locais. (VACCAREZZA, 2004; ZAUITH; OGATA; HAYASHI, 2011; DOMICIANO, 2019).

Na primeira metade do século $X X$, os países latino-americanos vivenciaram um processo de transferência de ciência e tecnologia importadas de maneira acrítica dos países desenvolvidos. O fomento dessas políticas estabeleceu uma dependência dos países subdesenvolvidos em relação à produção de ciência e tecnologia dos países desenvolvidos, sendo que nos países da América Latina não houve mudanças na dinâmica de inovação do conhecimento ou na economia local, pois as políticas de CT encontravam barreiras nas condições de desenvolvimento histórico e político da região e não correspondiam às necessidades econômicas e sociais (VACCAREZZA, 2004; ZAUITH; OGATA; HAYASHI, 2011; DOMICIANO, 2019).

Ainda como movimento, o CTS apresenta um panorama muito mais complexo na América Latina, como, por exemplo, um movimento acadêmico cognitivo com caráter de trabalho intelectual e de maior dependência das correntes internacionais de pensamento sobre o tema. São estudos que ganham notoriedade na incorporação das discussões de 
forma global, pela incorporação de bases teóricas das tradições americana e europeia, por exemplo (VACCAREZZA, 2004).

Porém, convém analisar como tem se dado a incorporação de bases teóricas e epistemológicas de outros contextos do movimento CTS para a América Latina, pois elas podem apresentar lacunas no que diz respeito aos problemas sociais, políticos, econômicos e ambientais relacionados com o desenvolvimento científico, tecnológico e sociais locais e regionais, diferentes daqueles encontrados nos chamados países desenvolvidos. Existe a preocupação de que essas regiões fiquem à mercê dos interesses internacionais vinculados ao conceito de desenvolvimento capitalista vigente, já que os pressupostos e objetivos do movimento CTS são importados de maneira acrítica (VACCAREZZA, 2004). Dessa forma, consideramos que tanto a transferência de CT quanto a incorporação de estudos das correntes internacionais sobre CTS precisam ser vistas com criticidade em meio aos desafios específicos de uma determinada região.

Auler (2011) chama a atenção para os desafios vinculados aos aprofundamentos conceituais, bem como a discussão de horizontes para o movimento CTS e suas repercussões no campo educacional. Assim, destaca a importância de uma participação social maior em defesa do redirecionamento do desenvolvimento científico e tecnológico. Inclusive resgata o pensamento do PLACTS em favor de políticas de desenvolvimento em CT marcadas pelas demandas da sociedade latino-americana.

Nestes termos, confirmamos a ideia de Linsingen (2007) e de Auler (2011), na qual vemos a necessidade de fomentar alternativas que ampliem o interesse das pessoas pela ciência e pela tecnologia, fornecendo meios para a formação cidadã, condizente com o contexto histórico e social da América Latina e, especificamente, do Brasil. Para isso, necessitamos iniciar uma cultura de participação da sociedade de forma mais qualificada, discutindo as concepções de cidadania, o modelo de sociedade, de desenvolvimento tecnológico, tendo em vista a situação social, econômica e cultural do país e, especialmente, observar as questões ambientais e os contextos em que ocorrem, levando em consideração a biodiversidade brasileira e os problemas que o desenvolvimento científico e tecnológico têm trazido para os ecossistemas.

Compreendemos, portanto, que esta discussão se aproxima do PLACTS, pois é um pensamento que leva em consideração as necessidades de desenvolvimento científico e tecnológico e o respeito aos conhecimentos e à cultura da população, especialmente, tratando-se de territórios e ecossistemas tão diversos como a Amazônia brasileira. Porém, além de assumir nossa proximidade com o caráter crítico, buscamos também o desenvolvimento de práticas de ensino voltadas para a formação de uma sociedade mais democrática, conforme se caracteriza o CTS no Brasil (ABREU; FERNANDES, MARTINS, 2013)

No Brasil, CTS tem-se traduzido para além de um movimento social ou de tradição acadêmica. Aqui as ideias do movimento passam a ser incorporadas à educação na década de 1990 e a produção sobre o campo tem desenvolvido vários aspectos. De acordo com Abreu, Fernandes e Martins (2013), o pensamento brasileiro em CTS está em processo de desenvolvimento, no qual autores nacionais se estabelecem como referência para os pesquisadores. Diferente do caráter crítico do PLACS, busca-se a consolidação de uma sociedade democrática, pela construção de práticas de cidadania e responsabilidade social. Também é característica a postura crítica diante das relações CTS, negando mitos salvacionista de ciência e tecnologia. Quanto à educação, está situado à realidade brasileira no que se refere às discussões curriculares e à estruturação de ensino. Ou seja, o que esses 
autores chamam de pensamento brasileiro em CTS tem se preocupado em produzir pesquisa para situações de ensino em ambientes formais e não formais como também na elaboração de um pensamento teórico autônomo.

Em relação aos termos utilizados, podemos perceber que o movimento ganha outras denominações, influenciadas pelos processos de ensino e aprendizagem: currículo CTS, educação CTS, abordagem CTS, entre outros (AULER; BAZZO, 2001; SANTOS; MORTIMER, 2001; STRIDER, 2012). Segundo Strider (2012), o termo "movimento" é usado para se referir ao campo do CTS no contexto em que surgiu enquanto movimento social. Já o termo "enfoque" está relacionado à ampliação do conceito para o campo educacional e o termo "abordagem" é usado para enfatizar a diversidade das relações CTS na educação científica.

Nesta discussão, optamos por utilizar, a denominação abordagem CTSA, acrescentando o "A", por compreender as diversas formas de abordar as relações CTSA no contexto do ensino de ciências, com ênfase nas questões ambientais. Contudo, respeitamos a referência utilizada pelos autores aqui citados como as denominações "enfoque CTS" e "educação CTS", ou seja, quando essas denominações aparecem no texto elas remetem a como são citadas nas obras referenciadas.

Convém destacar que, desde os primórdios, o movimento CTS tem respondido aos apelos de promover a consciência da emergência planetária em que nos encontramos. Contudo, a incorporação de "A" em CTS responde ao anseio de dar maior ênfase às questões ambientais relacionadas ao desenvolvimento científico e tecnológico e à importância de tratar 0 ambiente no ensino de ciências. Há divergências ${ }^{4}$ quanto à necessidade desta inclusão, pois, para alguns, a incorporação é desnecessária, já que o movimento CTS tem suas origens ligadas às investigações sobre os problemas causados pelo desenvolvimento científico e tecnológico ao ambiente (VILCHES; GIL-PÉREZ; PRAIA, 2011).

Porém, os autores que defendem a inclusão do " $\mathrm{A}$ " argumentam que a reflexão para as questões ambientais faz convergir os objetivos da educação ambiental e da abordagem CTSA para uma inovação educativa na tomada de decisão fundamentada sobre a emergência planetária para alcançar um futuro sustentável (VILCHES; GIL-PÉREZ; PRAIA, 2011). Logo, justificamos a incorporação de "A" em CTS, pois convida a evitar o reducionismo das relações entre ciência, tecnologia e sociedade e aponta as consequências ambientais dos processos científicos e tecnológicos, especialmente quando a referência das discussões é a Amazônia.

Consideramos que a abordagem CTSA tem um grande potencial para buscar melhorias para o ensino de ciências. As discussões até aqui apresentadas não têm a pretensão de esgotar as bases históricas e epistemológicas da abordagem CTSA, mas tão somente de extrair subsídios que indiquem seus princípios, principalmente os relacionados à sua origem, a saber: superar visões deformadas de ciência e tecnologia e promover uma cultura de participação. Passamos agora a apresentar nossas reflexões sobre a perspectiva do estudo implicado na pesquisa para tecer elos que ajudam a entender as seções seguintes.

\footnotetext{
${ }^{4}$ Ainda não existe um consenso sobre as siglas e as terminologias a serem utilizadas. Além de CTS e CTSA, incluem-se ainda CT (Ciência e Tecnologia), CTCA (Ciência, Tecnologia, Cultura e Ambiente) e outras para ampliar as representações de um movimento que busca em geral compreender contextos da vida real e sua relação com a Ciência e a Tecnologia (STRIDER, 2012; TOMAZELLO, 2009).
} 


\section{O sentido da implicação na pesquisa e no ensino de ciências}

O pressuposto básico desta discussão é que a pesquisa e o ensino de ciências por meio da abordagem CTSA perpassam pela implicação dos participantes, inclusive do professor e pesquisador. Trata-se, portanto, do reconhecimento do caráter histórico e epistemológico da abordagem CTSA, que traz consigo uma outra maneira de ver a ciência e a tecnologia, assim como a possibilidade de tomar como objeto de problematização e investigação processos nos quais o professor e pesquisador está envolvido.

Tomamos o sentido da palavra "implicado" como aquilo que está entrelaçado, envolvido e também situado ao contexto dos participantes. Assim, a perspectiva do estudo implicado tece relações entre a constituição do professor e pesquisador com o contexto de pesquisa e os problemas sociais vividos pelas comunidades e a necessidade de se discutir sobre ciência e tecnologia. Assim, por meio da abordagem CTSA não é possível pensar numa pesquisa aplicada, na qual os participantes e o contexto social, econômico, político e ambiental não estejam envolvidos.

Martins Filho e Narvai (2013) consideram que todo aquele que se vê na tarefa de produzir conhecimento científico é um sujeito implicado, visto a não-neutralidade da ciência. Ao assumir a tarefa de produzir conhecimento científico com abordagem CTSA, observamos que a perspectiva do estudo implicado se fortalece ao se ocupar de um tema cuja problematização requer a consideração de ser e de integrar os objetos de pesquisa. $\bigcirc$ problema e a discussão de soluções podem existir sem a presença dos participantes; mas, ao admitir que integramos coletivos, a presença de qualquer indivíduo altera o contexto, a forma de ver o problema social e de buscar soluções em ciência e tecnologia.

Em uma busca flutuante no catálogo de teses e dissertações da CAPES, utilizando como critério de busca as produções a nível de pós-graduação strictu sensu sobre os estudos que envolvem a abordagem CTSA não encontramos nenhum trabalho que mencione o termo "implicação" ou "implicado" no título, resumo ou palavras-chave. Porém, foi possível detectar alguns trabalhos sobre práticas de ensino por meio de temas do cotidiano dos alunos, sejam globais ou locais, como, a exemplo, Silva (2016). A referida autora elabora uma intervenção pedagógica com base nas reclamações sobre falta de água vivida pela comunidade escolar, tomando as convicções e conhecimentos da professora sobre esse problema, buscando avaliar as percepções, os questionamentos e os compromissos sociais envolvidos como propósito da educação CTS. Observamos que há uma perspectiva implicada da professora no estudo como sujeito que produz conhecimento dentro de um contexto do qual ela participa, que ela conhece e no qual interage.

Ao assumir a perspectiva do estudo implicado, retomamos Martins Filho e Narvai (2013), ou seja, reconhecemos a produção do conhecimento útil e relevante a partir do encontro com a práxis; contudo, levando em consideração o rigor e a ética da pesquisa com a "permanente análise do impacto que as situações vivenciadas exercem sobre a história do pesquisador e sobre o sistema de poder instituído" (p. 651). Assim, consideramos que é um olhar ampliado para esse tipo de pesquisa em educação - o professor não aplica um tema à revelia dos estudantes ou da comunidade escolar - o tema e os participantes estão envolvidos no contexto e isso é visível e desejável quando a pesquisa ocorre por meio da abordagem CTSA. 


\section{Elementos que vinculam a abordagem CTSA à perspectiva do estudo implicado}

Além de pensar a perspectiva do estudo implicado, propomos-nos a discuti-la, tomando como base alguns elementos da abordagem CTSA. Tais elementos surgem da elaboração dos cursos com enfoque CTS e que dão ênfase aos aspectos sociais do ensino de ciências, voltados para a formação para a cidadania, e são apresentados, originalmente, em Santos e Mortimer (2002) e Santos e Schnetzler (2015), a saber: os objetivos; interações entre ciência, tecnologia, sociedade; e estratégias de ensino.

\section{a) Objetivos}

O desenvolvimento da capacidade de tomada de decisão (SANTOS; SCHNETZLER, 2015) e a alfabetização científica dos cidadãos (SANTOS; MORTIMER, 2002) são os principais objetivos da abordagem CTS. São processos que auxiliam a pessoa a tomar decisões responsáveis na sociedade e atuar na solução de problemas. Podemos depreender que sugere envolvimento com o contexto socioambiental, seja ele de forma global ou local.

Destaca-se que o cumprimento desses objetivos envolve o desenvolvimento de valores e a ação social responsável com interesses coletivos, como de solidariedade, de fraternidade, de reciprocidade, de respeito ao próximo, de generosidade e aquele que consideramos um dos mais importantes: a consciência do compromisso social. São esses valores que se contrapõem aos valores da economia vigente e ao consumismo e é também por eles que se constituirão cidadãos comprometidos com a sociedade por um olhar crítico (SANTOS; MORTIMER, 2002).

A capacidade de tomada de decisão e o conhecimento e aplicação da linguagem científica devem, primeiramente, estar direcionados para evitar aplicações apressadas de inovações das quais se desconhece as consequências a longo e médio prazo, como historicamente aconteceu com o DDT, com o armazenamento de energia nuclear e emissão de CFCs e que hoje se configura, por exemplo, pela comercialização de produtos geneticamente modificados, a manutenção de ecossistemas naturais e a garantia de medicamentos e vacinas para todos. A participação dos cidadãos na tomada de decisões é permissível e necessária na atualidade para a garantia do princípio de precaução, na qual o desenvolvimento científico e tecnológico pode implicar em prejuízos para os seres humanos e para o ambiente. (CACHAPUZ et al., 2011).

As ideias de Bazzo (2012) ampliam o sentido dos objetivos da abordagem CTS para o resgate de valores humanos na difusão da cultura científica. O autor chama atenção para a formação desses valores na educação escolar mediante a aquisição de conhecimento científico. Apesar de suas ideias estarem direcionadas aos alunos do ensino médio, compreendemos que a essência dos escritos de Bazzo (2012) estão em apresentar a abordagem CTS como o elo entre a cultura científica e a humanística, e isso é possível em todas as etapas e modalidades da educação, seja para a formação da personalidade juvenil, para processos de desenvolvimento de capacidade de tomada de decisão ou na formação de professores que viabilizem tal função educacional.

De acordo com Bazzo (2012), precisamos de pessoas trabalhando em prol da construção do elo entre cultura científica e cultura humanística, o que, consequentemente, legitima a formação de professores e pesquisadores críticos, os quais não leem e "escrevem com «letras frias» para serem lançadas no mundo das tecnologias digitais ou esquecidas em 
folhas de papel" (p. 79), mas que são sensíveis em relação à busca de solução dos problemas humanos, por meio de mesclas teóricas e multirreferenciais.

Portanto, viver em sociedade, significa, inúmeras vezes, conviver com problemas de caráter científico e tecnológico. Muitas comunidades têm problemas com acúmulo de lixo, acesso à água potável, no trânsito, entre outros. As pessoas lidam diariamente com dezenas de situações e têm que decidir como fazê-lo. Contudo, essa decisão não se legitima apenas com pressupostos dos conhecimentos científicos e tecnológicos, mas também pela construção de valores humanamente universais de justiça, fraternidade e equidade.

Por isso, ao considerar a perspectiva do estudo implicado aos objetivos da abordagem CTSA, converte em refletir o envolvimento com a tomada de decisão por meio do letramento científico que se paute na leitura de mundo e na formação de leitores críticos. Isso pode significar mudança de postura com o reconhecimento dos problemas e a busca de solução para amenizá-los, considerando a complexidade das questões envolvidas no contexto.

b) Interações Ciência, Tecnologia, Sociedade e Ambiente

De acordo com Santos e Schnetzler (2015), a caracterização da abordagem CTS e a interação entre Ciência, Tecnologia e Sociedade se evidencia de modo interdisciplinar no ensino de ciências, o que difere da simples transmissão do conhecimento científico pela aplicação de atividades que não retratam as questões sociais e ambientais.

Isso significa, para Santos e Mortimer (2002), que os conceitos são estudados numa dimensão relacional, procurando evidenciar suas diferentes dimensões e a relação com as interações entre ciência, tecnologia e sociedade.

Para ajudar a compreender essas interações, buscamos as contribuições de Strider (2012), pois, assim como a autora, entendemos que essas interações precisam ser vistas por diversos enfoques, disciplinas, horizontes e perspectivas, considerando o caráter complexo e ambíguo que a ciência, a tecnologia e a sociedade têm desempenhado. Tal ambiguidade e complexidade se refletem no entendimento das relações CTS, nas atividades educacionais desenvolvidas e, possivelmente, nas pesquisas no campo, visto que não há neutralidade.

Strider (2012) defende que CTS não é mera discussão de ciência e tecnologia inseridas num contexto social, mas a articulação entre ambas em parâmetros que explicitam essa relação ao invés de reduzi-las às compreensões separadamente. Nesse sentido, a articulação se dá em três parâmetros: Racionalidade Científica, (b) Desenvolvimento Tecnológico e (c) Participação Social, na perspectiva do desenvolvimento de compromissos sociais.

A perspectiva dos compromissos sociais envolve a compreensão de problemas de diferentes naturezas, com condições de fazer uma leitura crítica e holística da realidade, possibilitando a intervenção sobre problemas reais, dos quais a escola, como instituição social, também faz parte. Isso implica em abordar de forma contextualizada o conhecimento científico e tecnológico de forma coerente com as questões do cotidiano, que envolvem aspectos ambientais, desenvolvimento econômico, atendimento de necessidades básicas de uma comunidade, participação em políticas públicas. Perpassa, também, pela sensibilização quanto à presença de ciência e tecnologia no mundo; dos aspectos técnicos; da história da ciência e da tecnologia; e das discussões de nãoneutralidade e salvacionismo (STRIDER, 2012). 
Dito isto, é possível inferir que, ao conhecer o contexto de pesquisa e ensino, o professor e pesquisador é capaz de promover transformações ao observar e questionar as relações de poder, hierarquia, controle a autoridade que podem estar manifestadas nas relações entre ciência e tecnologia, aprimorando estratégias focadas nessas questões.

c) Estratégias de ensino

O ensino por meio da abordagem CTSA inclui, além das estratégias tradicionais, o uso de jogos de simulação e desempenho de papeis, fóruns e debates, projetos individuais e de grupos, escrita de textos de diversos gêneros, palestras e ação comunitária. Também entram nesse grupo as visitas a espaços de educação não-formal, utilização de entrevistas e uso de mídias digitais (SANTOS; SCHNETZLER, 2015).

Tais estratégias reconfiguram os papeis em sala de aula: o professor deixa de ser o detentor do conhecimento científico e os estudantes se tornam agentes de sua aprendizagem, contribuindo para o desenvolvimento da capacidade de tomada de decisão e consolidação da formação para a cidadania (SANTOS; SCHNETZLER, 2015).

Estratégias de ensino por meio dessa abordagem podem ser por diversos temas e incluir conteúdos de ciências em maior ou menor proporção, mas, sobretudo, organizados em razão do problema social. Segundo Aikenhead (1994), revisado em Santos e Schnetzler (2015), envolve as seguintes etapas:

1) a introdução de um problema social;

2) a análise de uma tecnologia relacionada ao tema;

3) o conteúdo científico é definido em razão do tema social e da tecnologia;

4) a tecnologia é estudada em função do conteúdo apresentado;

5) a questão social é novamente discutida.

Concordamos com Santos e Schnetzler (2015) sobre a importância dessa sequência. Porém, acreditamos que ela deve ser adotada de forma crítica e na perspectiva do estudo implicado, com vistas a não criar estereótipos quanto à construção linear de conhecimentos e hierarquização dos elementos que constituem a sigla CTSA.

Não temos a pretensão de esgotar as discussões sobre diferentes propostas, mas tão somente enfatizar a ideia de que a abordagem CTSA se diferencia das propostas tradicionais de ensino por organizar os conteúdos científicos e tecnológicos em função do problema social e, dessa forma, considerar a perspectiva do estudo implicado ao refletir sobre quem observa o problema social: possivelmente aqueles indivíduos implicados no contexto, especialmente, o pesquisador que se constrói e reconstrói conforme as mudanças ocorrem e convidam às transformações.

\section{Tecendo outras discussões com a abordagem CTSA, na perspectiva do estudo implicado, para o ensino de ciências na Amazônia}

Ao trazer nosso olhar para a realidade da Amazônia, deparamo-nos com inúmeros desafios quanto às discussões para a educação em ciências, visto as peculiaridades e a diversidade da região, que se reflete nas escolas.

Outra questão importante está em como promover uma educação científica e humanizada diante das pressões econômicas, políticas, sociais e ideológicas que elaboram 
currículos e políticas públicas em educação sem considerar essa realidade. Uma realidade marcada pela diversidade, a qual não comporta uma única solução pensada pelas classes dominantes. Ainda vivemos uma realidade de importação de práticas pedagógicas e currículos, por vezes assépticas, assim como de ciência e tecnologia sem problematizar a que custos e que modelos de formação buscamos enquanto região.

Em termos de aprendizagem, a abordagem CTSA se configura como uma proposta promissora para o ensino de ciências na Amazônia, pois nos mostra condições para mudanças nas visões que se tem de ciência e tecnologia, bem como oferece possibilidades de letramento científico para as pessoas. Concordamos com Martins e Paixão (2011) ao dizerem que o ensino CTS se apresenta numa perspectiva construtivista de característica social e, assim, abandona os modelos de descoberta e os modelos internalistas de mudança conceitual. Por meio dessa perspectiva, os estudantes podem assumir um papel mais dinâmico e ativo na sociedade.

Tal proposição é evocada com a necessidade de desenvolver processos de participação ativa, na medida em que há uma identidade cultural dos envolvidos com as questões postas em discussão. Dessa forma, torna-se fundamental a contextualização do ensino, correlacionado com o contexto cultural no qual o estudante está inserido, de modo que ele tenha significado, oferecendo-se condições para pensar em soluções para os problemas com a identificação cultural e integração à escola (SANTOS; SCHNETZLER, 2015).

De acordo com Roso e Auler (2016), a participação com propósito de transformação social requer a problematização da sociedade capitalista e, para nós, principalmente, a problematização dos modelos de desenvolvimento propostos para a Amazônia, assim como, criticidade diante da produção de ciência e tecnologia para e pela região. Isso reforça a ideia de que a participação social deve buscar superar os problemas da realidade dos envolvidos, com o reconhecimento desses problemas, em contraposição a uma participação ingênua, a qual costuma ocorrer na pós-produção e na pós-implantação de projetos de desenvolvimento científico e tecnológico.

Além de corroborar com a contextualização do ensino e com o desenvolvimento de processos de participação ativa, é possível inferir que a abordagem CTSA, na perspectiva do estudo implicado, com o reconhecimento da identidade cultural, possibilita o resgatar dos saberes populares e observar sua utilidade para a construção do conhecimento científico. Retomando as palavras de Chassot (2014), os saberes populares são construídos baseados em empiria, pela observação, formulação de hipóteses e generalização. No entender de Nascibem e Viveiro (2015), o meio acadêmico costuma ignorar a cultura e os saberes populares e na escola isso não é diferente. Há um predomínio do ensino transmissivista e descontextualizado, negligenciando as relações entre ciência, tecnologia, sociedade e ambiente.

Nesse sentido, para haver um processo autêntico de mudanças no ensino de ciências, pelo reconhecimento e ressignificação dos saberes populares, o professor e pesquisador deve ser percebido e perceber-se como aprendiz, já que não há saberes mais ou menos importantes e, sim, saberes diferentes (FREIRE, 2019; DOMICIANO, 2019). Ressalta-se que essa perspectiva se aproxima dos pressupostos freireanos, ao propiciar uma base formativa, com a construção de condições sociais mais igualitária e menos excludentes, para tornar possível a formação do pensamento crítico (STRIDER, 2012).

De acordo com Auler (2001), torna-se imprescindível iniciar uma cultura de participação para além de fornecer informações. Para que isso seja possível, Strider (2012) argumenta 
que o processo de ensino e aprendizagem passa a ter outro enfoque: o de contribuir para a emancipação do homem enquanto ser capaz de discutir e agir. Assim, temos a referência ao processo dialógico, no qual a construção do conhecimento acontece pelo diálogo, pela problematização e, associada a estes, a ideia de transformação da realidade. Entendemos que esses três elementos são fundamentais quando se busca a formação de cidadãos críticos e atuantes, assim como, possibilitam reconhecer a cultura de uma região como a Amazônia e suas peculiaridades, a fim de pensar em práticas de pesquisa e ensino para a região.

Entretanto, segundo Domiciano (2019, p. 78), a prática da dialogicidade é um desafio, quando a cultura em um país é a do silêncio. Nestes termos, é essencial que o professor "vivencie a dialogicidade em um espaço democrático de falas e horizontal, para que esses se possam fazer dialógicos".

A ideia de dialogar e problematizar parte do pressuposto de que a construção do conhecimento começa por questionamentos (STRIDER, 2012). Entretanto, a real apropriação do conhecimento só acontece quando ele tem algum sentido para o estudante, ou seja, é necessário que os problemas façam parte da vida do estudante para que, por meio de rupturas, o conhecimento que possui seja confrontado com o conhecimento necessário para compreender e resolver os problemas (DELIZOICOV; ANGOTTI; PERNAMBUCO, 2011).

Assim, as atividades de ensino por meio da abordagem CTSA ganham destaque por terem como concepção a organização conceitual centrada em temas de relevância social, não com propósitos reducionistas, mas, sim, de ressignificá-los. As estratégias de ensino na abordagem implicam a participação ativa dos envolvidos para a construção de sua aprendizagem (SANTOS, 2007; SANTOS; SCHNETZLER, 2015).

Desse modo, constitui-se como possibilidade por meio da abordagem CTSA a estruturação do ensino por temáticas significativas, obtidas pelo processo de Investigação Temática Freiriana, a qual possibilita identificar a percepção de si e do mundo, bem como contribuir para a tomada de consciência. No contexto do ensino de ciências, o processo de Investigação Temática é retomado por Delizoicov, Angotti e Pernambuco (2011) para planejar e implementar atividades didático-pedagógicas, no qual são propostos os três momentos pedagógicos: Problematização inicial: visa à apresentação das situações reais e à sua ligação com os conteúdos científicos. Manifestação das concepções prévias das questões colocadas para a problematização. O professor é o mediador, concentrando-se em questionar posicionamentos. Nesse momento ocorre a necessidade de apropriação de novos conhecimentos; Organização do conhecimento: desenvolvimento dos conteúdos a partir do conhecimento científico. Compreensão científica das situações-problema; Aplicação do conhecimento: reinterpretação das situações iniciais e de outras que surgirem a partir do conteúdo escolar estudado.

Dentre as pesquisas na área do ensino de ciências que tem buscado desenvolver atividades com estudantes amazônicos nos três Momentos Pedagógicos, destacamos os trabalhos de Ribeiro (2016) e de Carvalho e Almeida (2019). Convém assinalar que Ribeiro (2016) e Carvalho e Almeida (2019) trazem para a pesquisa e o ensino temas de relevância para a região amazônica: a água para o consumo humano e a energia elétrica no ambiente doméstico, respectivamente. A região possui umas das maiores bacias hidrográficas do planeta, na qual estão localizadas grandes usinas hidrelétricas; porém, as pessoas costumam sofrer com problemas associados a esses temas. 
Ribeiro (2016) traz o conteúdo por meio do tema Água para o Consumo Humano, o qual apresenta um tema de relevância social, demonstrado por meio de uma pesquisa exploratória na comunidade escolar, problematizando e estabelecendo relações com determinados conceitos científicos sobre a água, necessários para sua abordagem. Trata-se de uma reorganização de conteúdos e de estratégias de ensino em função da questão social de falta de água numa região de abundância de rios de água doce. Os estudantes são convidados a relacionar os conceitos científicos aos problemas sociais e exploram diversos aspectos da vida em sociedade. Ao final da atividade, os alunos produziram uma carta direcionada para as autoridades responsáveis pelo abastecimento de água na comunidade, expondo suas ideias com possíveis soluções para os problemas discutidos em sala de aula.

Carvalho e Almeida (2019) também pesquisam a abordagem CTS aliada ao ensino por meio de temas, com a problematização do consumo de energia elétrica no ambiente doméstico. Por meio do estudo foi possível inferir que os estudantes perceberam os principais problemas que envolvem o consumo de energia elétrica em suas residências e formas de atenuar esses problemas.

Além da Investigação Temática e dos três Momentos pedagógicos, podemos dizer que a perspectiva do Ensino por Pesquisa (EPP) também se configura como um modo de proporcionar um processo didático-metodológico em conjunto com as estratégias de ensino CTSA. A relevância na abordagem de situações-problema do cotidiano permite a formação de atitudes e valores. Sobretudo na educação básica, o EPP deve, tanto quanto possível, iniciar-se nos problemas sociais ou ambientais (CACHAPUZ; PRAIA; JORGE, 2002), os quais, a nosso ver, têm destaque na Amazônia, caracterizados pelos inúmeros problemas: saneamento básico, fornecimento de água potável, desmatamento, uso do solo e mineração, modificações ambientais, fenômenos naturais que impactam a vida cotidiana com o fenômeno das marés, entre outros.

O EPP considera a existência de três momentos fortes para seu desenvolvimento, articulando-se com ciclos de aprendizagem de modo a possibilitar retornos necessários ao professor, a saber: a Problematização que tem pólos no currículo intencional, nos saberes populares e nas situações problemáticas no âmbito CTSA; as Metodologias de Trabalho que ora têm ênfase no estudante, ora no professor; e a Avaliação Terminal da Aprendizagem e do Ensino com a avaliação dos produtos, ou seja, sobre os conhecimentos, capacidades e valores, e a avaliação dos processos, de como ocorreu o ensino e a aprendizagem (CACHAPUZ; PRAIA; JORGE, 2002).

Pensar estratégias de ensino a partir da introdução de um problema social é construir caminhos para a formação para a cidadania. Nessa perspectiva, não basta fazer a crítica pura aos currículos e políticas públicas. É desejável que o professor e pesquisador adote a perspectiva do estudo implicado a fim de reconhecer o seu envolvimento e também seus limites com a pesquisa e o ensino.

Especificamente para o ensino, o que discutimos até aqui se faz pertinente para refletirmos sobre alternativas que atendam à diversidade, levando em consideração a história de formação dos diferentes municípios e a construção de um modelo de desenvolvimento econômico, social e ambiental justo e democrático. A Amazônia não é um sistema hegemônico de floresta e rios. Existe diversidade de ambientes, de formação de territórios e de culturas. Isso nos convida a pensar em estratégias de ensino interdisciplinares, principalmente na perspectiva dos processos de letramento científico e 
sua relação com outros processos de letramento importantes para a compreensão dos problemas verdadeiros no seu contexto real e a ação social característicos do ensino CTSA (SANTOS SCHNETZLER, 2015).

Corroboramos com a ideia de que especificar bem esses contextos converge com o entendimento de um contexto específico de vida e de cultura. Partindo da discussão sobre a perspectiva do estudo implicado por meio da abordagem CTSA, adotar como parte do campo empírico a região amazônica e abordar temas de relevância social para a região, contextualizando-os, imprime na pesquisa uma identidade sociocultural, associada a demandas sociais de letramento científico numa região de grande potencial turístico e econômico, porém carente de meios para inserção na cultura científica, respeitando a cultura e os conhecimentos tradicionais e de poder de tomada de decisão baseada em conhecimentos científicos.

\section{Considerações}

Tendo como ancoragem a educação científica e tecnológica, buscamos neste artigo discutir a abordagem CTSA, na perspectiva do estudo implicado, para a pesquisa e o ensino de ciências na Amazônia brasileira. Assim é possível dizer que a referida abordagem se constitui relevante, pois, permite olhar o contexto de vida e de cultura dos participantes da pesquisa e das propostas de ensino, auxiliando em decisões que tendem a ser transformadas conforme o cenário social sofre modificações. Dito de outra forma: é possível pensar em um ensino de ciências que abranja a complexidade e a especificidade dos povos da região por meio da abordagem CTSA, já que esta permite o envolvimento ético do professor e pesquisador, a contextualização dos problemas e a busca de soluções para superá-los.

Temos consciência de que o papel do pesquisador implicado está impregnado de subjetividade e da sua visão de ensino, aprendizagem e da bagagem teórica que o constitui. Porém, ao nos apropriarmos da perspectiva do estudo implicado, observamos um movimento de reconstrução de visão de ciência, de tecnologia, de pesquisa e de ensino na perspectiva da transformação.

Ensinar e pesquisar no campo do ensino de ciências na Amazônia envolve, sobretudo, elementos importantes da abordagem CTSA, como a possibilidade de participação ativa por meio da identificação cultural, a dialogicidade pelo reconhecimento e ressignificação dos saberes populares e a problematização, associadas à ideia de transformação da realidade. Tais elementos se constituem importantes na formação de pessoas críticas e podem propiciar a diminuição dos estereótipos de dependência de conhecimento científico e tecnológico e de subcultura da região.

Destacamos que por meio da abordagem CTSA não seria possível pensar numa pesquisa aplicada, pois, se precisamos partir de uma questão social articulada à ciência e à tecnologia, devemos trazer um olhar holístico e complexo para a situação, levando em consideração todo o contexto e o envolvimento pessoal do pesquisador com o objeto de estudo. Não cabe, assim, aplicar soluções acabadas e acríticas para contextos específicos, especialmente quando levamos em consideração uma região tão diversificada como a Amazônia. Por isso, pensar em estratégias de ensino que envolvam temas de relevância social e o EPP se torna interessante por afastar práticas tradicionais e assépticas de ensino. 
Ao assumir a perspectiva do estudo implicado podemos produzir conhecimento útil e relevante a partir do encontro com a práxis, levando em consideração o rigor e a ética da pesquisa. Assim, é preciso investir na formação de professores pesquisadores para o ensino de ciências que compreendam a perspectiva do estudo implicado na educação em ciências por meio da abordagem CTSA como um caminho promissor para a autonomia crítica, ética e justa, observando as questões do desenvolvimento científico e tecnológico, possibilitando a formação para a cidadania e para a tomada de decisão nos processos que envolvem a aproximação entre a pesquisa e o ensino de ciências.

\section{Referências}

ABREU, T. B.; FERNANDES, J. P.; MARTINS, I. Levantamento sobre a produção CTS no Brasil no período de 1980-2008 no campo de Ensino de Ciências. Alexandria: Revista de Educação em Ciência e Tecnologia, v. 6, n.2, p. 3-32, jun, 2013.

AIKENHEAD, G. S. What is STS science teaching? In: SOLOMON, J., AIKENHEAD, G. STS education: international perspectives on reform. New York: Teachers College Press, p.47-59, 1994.

ARAÚJO, A. B.; SILVA, M. A. Ciência, tecnologia e sociedade; trabalho e educação: possibilidades de integração no currículo da educação profissional tecnológica. Revista Ensaio. V. 14, n. 01, p. 99-112, jan./abr., 2012.

AULER, D. Novos caminhos para a educação CTS: ampliando a participação. In: SANTOS, W. L. P.; AULER, D. CTS e Educação Científica: desafios, tendências e resultados de pesquisa. Brasília: editora da Universidade de Brasília, 2011.

AULER, D.; BAZZO, W. A. Reflexões para a implementação do movimento CTS no contexto educacional brasileiro. Ciência \& Educação, v.7, n.1, p.1-13, 2001.

BAZZO, W. A. Cultura científica versus humanística: CTS é o elo? Revista Iberoamericana de Educación. n. 58, p. 61-79, 2012.

CACHAPUZ, A. F., PRAIA, J.; JORGE, M. Perspectivas de ensino: caracterização e evolução. Ciência, Educação em Ciência e Ensino de Ciências. Lisboa: Ministério da Educação, 2002.

CACHAPUZ, A.; GIL-PEREZ, D.; CARVALHO, A. M. P.; PRAIA, J; VILCHES, A. A necessária renovação do ensino de Ciências. $3^{a}$ Ed. São Paulo: Cortez, 2011.

CARVALHO, R. H.; ALMEIDA, A. C. P. C. Consumo doméstico de energia elétrica por meio da abordagem Ciência, Tecnologia e Sociedade. Desenvolvimento Curricular e Didática, v. 11, n. 2, p. 843-861, ago., 2019.

CEREZO, J. A. L. Ciência, Tecnologia e Sociedade: o estado da arte na Europa e nos Estados Unidos. In: SANTOS, L. W. (et al). Ciência, Tecnologia e Sociedade: o desafio da interação. Londrina: IAPAR, p. 11- 46, 2004.

CHASSOT, A. Alfabetização científica: questões e desafios para a educação. $6^{a}$ ed. ljuí: Unijuí, 2014.

DAGNINO, R., THOMAS, H. e DAVYT, A. El pensamiento en Ciencia, tecnología y sociedad en América Latina: una interpretación política de su trayectoria. Redes, v.3, n.7, 1996. 
DELIZOICOV, D.; ANGOTTI, J. A.; PERNAMBUCO, M. M. Ensino de Ciências: fundamentos e métodos. São Paulo: Cortez, 2011.

DOMICIANO, T. D. Enfoque CTS no curso de licenciatura em Ciências da UFPR. Dissertação

(Mestrado em Educação em Ciências e em Matemática), Universidade Federal do Paraná, Curitiba, 2019

FREIRE, P. Pedagogia da autonomia: saberes necessários à prática educativa. 59a ed. Rio de Janeiro: Paz e Terra, 2019.

LINSINGEN, I. Perspectiva educacional CTS: aspectos de um campo em consolidação na América Latina. Ciência e Ensino, v. 1, n. especial, nov., 2007.

LOUREIRO, V. R. Amazônia: uma história de perdas e danos, um futuro a (re)construir. Estudos Avançados, v. 16, n. 45, p. 107-121, 2002.

MARTINS, I. P.; PAIXÃO, M. de F. Perspectivas atuais Ciência-Tecnologia-Sociedade no ensino e na investigação em educação em ciências. In: SANTOS, W. L. P.; AULER, D. (org.). CTS e educação científica: desafios, tendências e resultados de pesquisa. Brasília: Editora Universidade de Brasília, p. 135-160, 2011.

MARTINS FILHO, M. T.; NARVAI, P.C. O sujeito implicado e a produção de conhecimento científico. Saúde debate, v. 37, n. 99, p.646-654, 2013.

NASCIMENTO, F.; FERNENDES, H. L.; MENDONÇA, V. M. O ensino de Ciências no Brasil: história, formação de professores e desafios atuais. HISTEDBR, Campinas, v. 39, p. 225-249, set., 2010.

NASCIBEM, F. G; VIVEIRO, A. A. Para além do conhecimento científico: a importância dos saberes populares para o ensino de ciências. Interfaces, n. 39, p. 285-295, 2015.

RIBEIRO, D. N. C. A água para o consumo humano: ensino por meio de temas com abordagem em Ciência, Tecnologia, Sociedade e Ambiente. 2016. 151 f. Dissertação (Mestrado em Docência em Educação em Ciências e Matemática) - Universidade Federal do Pará, Belém, 2016.

ROSO, C. C.; AULER, D. A Participação na Construção do Currículo: Práticas Educativas Vinculadas ao Movimento CTS. Ciências \& Educação, Bauru, v. 22, n. 2, p. 371-389, 2016.

SANTOS, W. L. P. Educação Científica: uma revisão sobre suas funções para a construção do conceito de letramento científico como prática social. Revista Brasileira de Educação, v. 12, n. 36, p. 474-492, set/dez., 2007.

SANTOS, W. L. P. Significados da educação científica com enfoque CTS. In: SANTOS, W. L. P.; AULER, D. CTS e Educação Científica: desafios, tendências e resultados de pesquisa. Brasília: editora da Universidade de Brasília, 2011.

SANTOS, W. L. P. Educação CTS e Cidadania: confluências e diferenças. Amazônia: revista de educação em ciências e matemáticas, v. 9, p. 49-62, jul./dez., 2012.

SANTOS, W. L. P.; MORTIMER, E. F. Tomada de decisão para ação social responsável no ensino de ciências. Ciência \& Educação, Bauru, v. 7, n. 1, p. 95-111, 2001. 
SANTOS, W. L. P.; MORTIMER, E. F. Uma análise de pressupostos teóricos da abordagem CTS (Ciência-Tecnologia-Sociedade) no contexto da educação Brasileira. Ensaio: pesquisa em educação em ciências, v. 2. p. 133-162, 2002.

SANTOS, W.L.P.; SCHNETZLER, R. P.; Educação em Química: compromisso com a cidadania. 4 ed. ljuí: Ed. Inijuí (RS), 2015.

SILVA, R. L. J. Tema água: uma contribuição para o desenvolvimento de percepções, questionamentos e compromissos sociais. 2016. 129 f. Dissertação (Mestrado Profissional em Ensino de Ciências) - Universidade de Brasília, Brasília, 2016.

STRIDER, R. B. Abordagem CTS na educação científica no Brasil: sentidos e perspectivas. 2012. 283 f. Tese (Doutorado em Interunidade em Ensino de Ciências) - Universidade de São Paulo, São Paulo, 2012.

TOMAZELLO, M. G. C. O movimento Ciência, Tecnologia, Sociedade - Ambiente na educação em Ciências. In: I Seminário Internacional de Ciência, Tecnologia e Ambiente, 2009, Cascavel (PR), Anais..., Cascavel (PR), 2009.

VACCAREZZA, Leonardo Sílvio Ciência, Tecnologia e Sociedade: o estado da arte na América Latina. In: SANTOS, Lucy Woellner dos (et al). Ciência, Tecnologia e Sociedade: o desafio da interação. Londrina: IAPAR, 2004, p. 47- 84

VILCHES, A.; GIL-PERÉZ, D.; PRAIA, J. Do CTS ao CTSA: education por um futuro sostenible. In: SANTOS, Wildson L. P., AULER, D. (Orgs.). CTS e educação científica: desafios, tendências e resultados de pesquisa. Brasília: Editora Universidade de Brasília, 2011. p. 185-209.

ZAUITH, G.; OGATA, M. N.; HAYASHI, M. C. P. I. Um breve panorama sobre a educação CTS no Brasil. In: HOFFMAN, W. A. M. (org.). Ciência, Tecnologia e Sociedade: desafios da construção do conhecimento. São Carlos: EduFSCar, 2011, p. 21-38. 